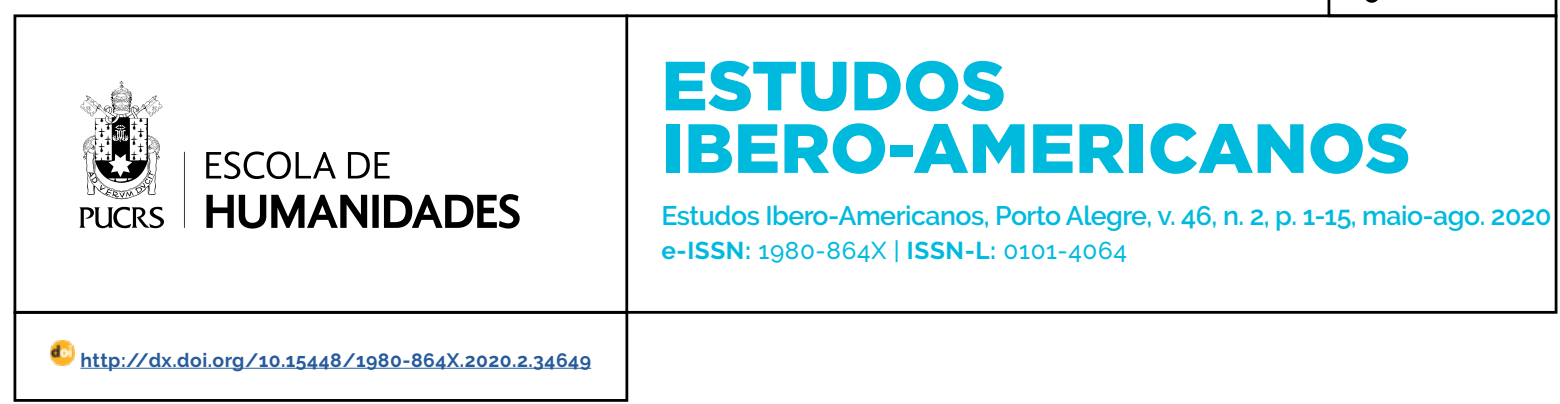

\title{
Os "novos bandeirantes" em marcha: o jornal Anhanguera como expressão do ideário bandeirista
}

\author{
Los "nuevos bandeirantes" en marcha: el periódico Anhanguera como expresión del \\ ideario bandeirista
}

The "new bandeirantes" in march: the newspaper Anhanguera like expression of

bandeirista ideas

\section{George Leonardo \\ Seabra Coelho ${ }^{1}$}

orcid.org/0000-0002-3166-4008

george.coelho@hotmail.com

Recebido em: 27 ago. 2019.

Aprovado em: 17 mar. 2020

Publicado em: 25 ago. 2020

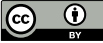

Artigo está licenciado sob forma de uma licença Creative Commons Atribuição 4.0 Internacional.
Resumo: No presente artigo, avaliaremos a importância do jornal Anhanguera como principal veículo midiático de divulgação do ideário do Movimento Bandeira em meados de 1937. Para tanto, discutiremos as bases ideológicas desse movimento, seus membros e a forma de divulgação de seu ideário e, ao mesmo tempo, apontaremos como esse jornal foi recebido entre militares e civis. Um último ponto de destaque desse artigo será a forma como os redatores do jornal Anhanguera criticavam a figura de Getúlio Vargas e defendiam a candidatura de Armando de Salles à Presidência da República. Para que seja possivel o desenvolvimento desse estudo, contaremos com as contribuições de Norbert Elias, Roger Chartier e Tania Regina de Luca, de modo que, esses autores nos auxiliarão no entendimento da articulação de uma "sociedade de indivíduos" através do jornal Anhanguera, a qual tem como habitus social a apropriação das representações literária do bandeirante paulista recheada por representações políticas.

Palavras-chave: Cultura. Bandeirante. Ideologia. Política.

Abstract: In this article, we will evaluate the importance of the Anhanguera newspaper as the main media vehicle for the dissemination of the ideology of the Flag Movement in the middle of 1937. To this end, we will discuss the ideological bases of this movement, its members and the way of disseminating its ideas, at the same time, we will point out how this newspaper was received between military and civilians. A final highlight of this article will be the way the editors of the newspaper Anhanguera criticized the figure of Getúlio Vargas and defended the candidacy of Armando de Salles to the Presidency of the Republic. In order to develop this study, we will count on the contributions of Norbert Elias, Roger Chartier and Tania Regina de Luca, so that these authors will help us to understand the articulation of a "society of individuals" through the Anhanguera newspaper, which has as social habitus the appropriation of the literary representations of the bandeirante paulista stuffed by political representations.

Keywords: Culture. Bandeirante. Ideology. Politics.

Resumen: En el presente artículo, evaluamos la importancia del periódico Anhanguera como principal vehículo mediático de divulgación del ideario del Movimiento Bandeira a mediados de 1937. Para ello, discutiremos las bases ideológicas de ese movimiento, sus miembros y la forma de divulgación de su ideario y, al mismo tiempo, apuntaremos cómo ese periódico fue recibido entre militares y civiles. Un último punto destacado de ese artículo será la forma en que los redactores del periódico Anhanguera criticaban la figura de Getúlio Vargas y defendian la candidatura de Armando de Salles a la Presidencia de la República. Para que sea posible el desarrollo de este estudio, contará con las contribuciones de Norbert Elias, Roger Chartier y Tania Regina de Luca, de modo que estos autores nos ayudarán en el entendimiento de la articulación de una "sociedad de indivíduos" a través del diario Anhanguera, que tiene como habitus social la apropiación de las representaciones literarias del bandeirante paulista rellenada por representaciones políticas.

Palabras clave: Cultura. Bandeirante. Ideología. Política. 


\section{Introdução}

No que diz respeito à situação política brasileira após o "Movimento de 30", Lúcia Lippi de Oliveira (1980) e Ângela de Castro Gomes (1980) consideram que o Governo Provisório teve de mediar os interesses de diferentes grupos e, como não havia uma força organizada, ficou sujeito às diversas influências. De outro lado, esses anos são definidos por Sônia Regina de Mendonça (1990) como um periodo de "crise política aberta". A autora aponta que, como nenhum grupo político tornou-se hegemônico em sucessão à antiga ordem, o novo governo atuou com relativa autonomia face aos interesses em disputa. Mesmo com a relativa autonomia do Governo Federal, vários acontecimentos - a Revolução Paulista de 1932, a Constituição de 1934 e a Intentona Comunista - e movimento politicos - o Integralismo, o Comunismo e a Democracia Liberal - foram postos na arena politica. Frente às novas relações entre o Estado e a sociedade - seja na tentativa de eliminar os elementos oligárquicos, seja no surgimento de novos projetos políticos -, essas autoras concordam que esse momento foi propício para a atuação política de novos grupos.

Segundo Ângela de Castro Gomes (1980), não é incomum, na história do Brasil, a periodização que toma como bloco coeso o periodo que vai de 1930 a 1945. Segundo essa visão, o "Movimento de 1930" assinalaria um ponto de partida, rompendo definitivamente com o passado e inaugurando um projeto político revolucionário. No pós-1930, o golpe de 1937 é tomado como reinício revolucionário, "sua marca principal é a consecução lógica do movimento de 1930 e, nesse sentido, os sete anos que o antecedem passam a ser a antecâmara de sua presença inevitável", sendo 1945, "outro ponto de cisão e de partida renovadora" (GOMES, 1980, p. 24). De acordo com a autora, essa leitura apaga da memória histórica as marchas e contramarchas do periodo que vai de 1930 a 1937. Ao reexaminar os conflitos políticos na década de 1930, este artigo pretende esclarecer a articulação de diversos sujeitos em torno do jornal Anhanguera.

O estudo do jornal Anhanguera é importante para apresentar a atuação política desses sujeitos no combate ideológico contra o Comunismo, o Integralismo e à Democracia Liberal, bem como, na defesa da candidatura de Armando de Salles à Presidência da República, em 1937. Através da leitura desse periódico, veremos como ocorreu a intertextualidade entre literatura e política, tendo no uso de ilustração/charge, um dos suportes para divulgação das bases ideológicas dos "novos bandeirantes". Acreditamos que, por meio da leitura do desse periódico, reconstruiremos parte da "sociedade de indivíduos" reunida em torno do Movimento Bandeira.

Ao lançar mão das proposições de Norbert Elias (1994), a noção de "sociedade de indivíduos" sugere uma questão central neste trabalho: o estudo da relação entre a pluralidade de pessoas e a pessoa singular, assim como, abre espaço para entender a pessoa singular como pluralidade. Seguindo esse raciocínio, levaremos em conta a relação entre um individuo singular - Cassiano Ricardo - e a pluralidade de sujeitos envolvidos na publicação do referido jornal. De modo geral, essa concepção nos auxiliará no entendimento das formas como sujeitos individuais ligavam-se uns aos outros em uma pluralidade e, concomitantemente, a situação desses mesmos sujeitos no interior da sociedade.

Juntamente com as posições acima descritas, Roger Chartier (2002) também nos oferece caminhos para entendermos a organização do jornal Anhanguera. Chartier compreende que se deve dar atenção às condições de produção, às diferentes relações entre a obra e seu criador, entre a obra e a sua época e, entre as diferentes obras da mesma época. Tal proposta parte da ideia de "consumo cultural" como "outra produção", a qual é um espaço aberto às literaturas múltiplas. A partir dessa concepção, Chartier constrói as bases para a noção de apropriação, a qual pode ser entendida como a compreensão dos usos

\footnotetext{
2 A denominação "novos bandeirantes" e "bandeiristas" serão utilizadas para nos referirmos aos integrantes ou simpatizantes do ideário do Movimento Bandeira.
} 
e das interpretações dos textos. De acordo com essa proposta, o pesquisador deve dar atenção às diferentes formas como os textos foram apreendidos e manipulados. Nessa perspectiva, a significação dos textos - em nosso caso, do jornal Anhanguera - depende das capacidades, dos códigos e das convenções de leitura das diferentes comunidades e públicos e, também, das "variações entre a significação, a interpretação e as apropriações plurais que sempre inventam, deslocam, subvertem" os enunciados (CHARTIER, 2002, p. 259). Com base nessa proposta, recuperaremos a história das diferentes modalidades da apropriação dos enunciados e dos diferentes sujeitos presentes na organização do jornal Anhanguera.

A partir da concepção de "sociedade de indivíduos" e da "apropriação dos enunciados" é que avaliaremos a importância do jornal Anhanguera como principal veículo midiático de divulgação do ideário do Movimento Bandeira. Para tanto, dividiremos este artigo da seguinte forma. No tópico, "Os 'novos bandeirantes' em marcha: a organização do Movimento Bandeira e do jornal Anhanguera", apresentaremos as bases ideológicas do Movimento Bandeira, seus membros e as formas de divulgação de seu ideário. Nesta seção, destacaremos os assuntos, os colaboradores, os editoriais, as colunas, com quem o jornal Anhanguera dialogava e sua relação com outros periódicos. No segundo tópico, "Repercussão do ideário dos 'novos bandeirantes' entre militares e civis", discutiremos a forma como esse periódico informava sobre a recepção do ideário bandeirista entre militares e civis. No último tópico, "Os bandeiristas se lançam na campanha presidencial de 1937", veremos como os "novos bandeirantes" apresentaram suas críticas a Getúlio Vargas e, como eles defenderam a candidatura de Armando de Salles à Presidência da República.
Frente à essa organização, convidamos o leitor a conhecer esse movimento político através das páginas do jornal Anhanguera.

\section{Os "novos bandeirantes" em marcha: a organização do Movimento Bandeira e do jornal Anhanguera}

O Movimento Bandeira foi organizado por Cassiano Ricardo e Menotti del Picchia entre 1935 e 1937. O ideário desse grupo apropriou-se de uma série de enunciados literários verde-amarelos ${ }^{3}$ para combater o Comunismo, o Integralismo e a Democracia Liberal. Ao combater essas ideias, os lideres bandeiristas defendiam a instauração do Estado Forte e da Democracia Social Nacionalista. Um terceiro ponto importante do ideário desse grupo era a defesa pela candidatura de Armando de Salles à Presidência da República nas eleições marcadas para 1938. A partir desta observação, podemos compartilhar com as concepções de Ângela de Castro Gomes e Lúcia Lippi de Oliveira ao afirmar que a década de 1930 abriu ao campo das ideias políticas novas possibilidades de organização da sociedade. Tendo em vista essa proposição, destacamos que Cassiano Ricardo - um dos lideres do Movimento Bandeira ${ }^{4}$ - adaptou suas posições literárias à nova realidade política nacional.

Como apontado, a estruturação do ideário político e literário dos "novos bandeirantes" tem origem no grupo verde-amarelo, tanto na articulação das ideias, quanto na composição dos integrantes, com exceção de Plínio Salgado que se tornaria o principal lider do movimento Integralista. Paralelamente ao principio de incorporar a atualidade sem quebrar as tradições, a valorização das coisas brasileiras e a crítica do estrangeirismo, vemos que a defesa da arte de cunho político complementa a base ideológica dos bandeiristas. Na apropriação do "mito bandeirante"

3 O ponto alto, em termos de sistematização dos pressupostos do verde-amarelismo, foi a coletânea O Curupira e o Carão (1927). Nessa coletânea, Cassiano Ricardo, Menotti del Picchia e Plinio Salgado inauguram a luta do presente contra o passado, mas o espírito estético do presente defendido pelo grupo verde-amarelo buscava de distanciar do "extremismo" de Mário de Andrade e da "estética de importação" de Oswald de Andrade. Para a triade verde-amarela, somente com a destruição do passadismo e com o distanciamento das influências estrangeiras se poderia dar início a construção de uma arte moderna e nacional.

4 Ao estudar o Movimento Bandeira, Maria L. Guelfi (1987) considera que esse grupo se erigia como terceira opção contra o Comunismo e o Integralismo, pois oferecia um modelo político-cultural "mais ajustado" à condição brasileira. Nesse ponto, discordamos dessa proposição, uma vez que os bandeiristas não se colocavam simplesmente como terceira via, mas como uma quarta via frente ao Comunismo, Integralismo e à Democracia Liberal. 
como plataforma política, os "novos bandeirantes" evocavam a relação entre o tempo - passado e presente - e o espaço - região paulista -, bem como, entre a tradição e o moderno.

O manifesto 5 dos "novos bandeirantes" publicado em 1936 é um documento fundamental para entender o ideário dos bandeiristas. Esse manifesto foi assinado por Cassiano Ricardo, Menotti del Picchia, José de Alcântara Machado, Vicente Ráo, Rubens do Amaral, Mário de Andrade, Guilherme de Almeida, Paulo Prado, Fonseca Teles, Plinio Barreto, Reynaldo Porchat, Almeida Prado, Taunay, Paulo Setúbal e Valdomiro Silveira. No referido Manifesto, encontramos as origens regionais e literárias do grupo, as quais partem de São Paulo e do "espírito renovador" da Semana de Arte Moderna de 1922. No que concerne ao movimento literário da Semana de 1922, o Manifesto informa que

[...] ela provocou o abalo fecundo [...] em todos os centros da atividade brasileira, destruiu a velha mentalidade literária e criou a possibilidade de se erguer, num campo espiritual mais aderente à nossa realidade política, artística e mesmo econômica, a estrutura vitoriosa e forte de um Brasil novo (MANIFESTO BANDEIRA, 1936 apud MONTEIRO, 2003, p. 391).

Os intelectuais reunidos em torno do movimento defendiam a tese de que o Brasil deveria encontrar o seu caminho como fizeram os bandeirantes paulistas. Segundo esse documento, "esta [nova] Bandeira reunirá, em cooperação harmoniosa, todas as inteligências criadoras contra todas as concepções alheias ao clima do nosso espírito e contrárias às finalidades nacionais" (MANIFESTO BANDEIRA, 1936 apud MONTEIRO, 2003, p. 390). Tal "cooperação harmoniosa" sustentará um movimento "destinado a salvaguardar a expressão original da alma brasileira e a fixar nossa unidade espiritual, sem a qual não haverá unidade política" (MANIFESTO BANDEIRA, 1936 apud MONTEIRO, 2003, p. 390). Para os bandeiristas, São Paulo daria a orientação dos caminhos da nação, uma vez que o Movimento Bandeira - assim como as "Bandeiras do século XVIII" e a "Semana de 1922" - foi fruto da "arrancada da mentalidade paulista para a fixação e defesa [...] da Pátria" (MANIFESTO BANDEIRA, 1936 apud MONTEIRO, 2003, p. 392). Esse Manifesto afirmava que era indispensável retomar o pensamento por meio da "tradição bandeirante" e atender ao sentido desse pensamento, colocando-o em "função social e política". No Brasil moderno ${ }^{6}$, os "novos bandeirantes" afirmavam que somente a tradição daria o caminho para a criação de "todo pensamento em função social" e a História daria a "inspiração e o prestígio de seus exemplos" (MANIFESTO BANDEIRA, 1936 apud MONTEIRO, 2003, p. 391).

O conjunto discursivo do Manifesto do Movimento Bandeira defende a união entre a tradição - heróis míticos do passado paulista - e o Brasil moderno - literatura modernista e industrialização - como meio de solucionar os dilemas políticos do presente. De modo mais claro, a associação entre tradição/moderno através da apropriação e da atualização dos "heróis geográficos" ao contexto político da década de 1930 - foi reorientada como exemplo histórico a serem retomados no combate às "ideologias forasteiras" no presente. Sendo assim, o "mito bandeirante" foi apropriado - em uma relação direta entre a literatura e a política como material simbólico para a elaboração de um projeto político-cultural para a Nação em meados da década de 1930.

Os bandeiristas organizaram diversas formas de divulgar seu ideário, entre eles, o Departamento Cultural da Bandeira que publicaria uma série de obras ensaísticas de seus membros, entre elas: O Brasil no original (1935), de Cassiano Ricardo; Exposição do pensamento bandeirante (1936), de Menotti del Picchia; O Estado brasileiro, de Candido Motta Filho; Capitalismo e economia nacional, de Aben-Assar Neto; a Filosofia da arte brasileira, de Guilherme Figueiredo. Apesar da

\footnotetext{
5 Esse manifesto foi transcrito no sexto número da revista S. Paulo (1936) e no jornal Anhanguera. Esse manifesto também pode ser encontrado no livro Cassiano: fragmentos para uma biografia de. Amilton Maciel Monteiro (2003).

6 No poema Martim Cererê (1928) de Cassiano Ricardo inicia, no campo literário, a fundamentação do que seria o Brasil moderno. De modo geral, a ideia de um Brasil moderno é o resultado de dois acontecimentos: a "Semana de 1922" e o processo de industrialização pela qual passava o estado de São Paulo
} 
organização desse Departamento, a principal forma de divulgação do programa bandeirista em 1937 foi o jornal Anhanguera.

O jornal Anhanguera foi dirigido por Cassiano Ricardo, Menotti del Picchia e Candido Motta Filho. Tinha como redator principal Osmar Pimentel, Guilherme Figueiredo era o crítico literário e Belmonte como ilustrador e, a partir do sexto número, Didio Valiengo assume a função de diretor gerente. Nesse periódico eram divulgadas as ações do grupo, as listas e comentários de colaboradores, a opinião sobre Getúlio Vargas, a defesa da candidatura de Armando de Salles à Presidência e, principalmente, a oposição ao Comunismo, ao Integralismo e à Democracia Liberal.

Concordamos com Tania Regina de Luca (2008) ao defender que o jornal - enciclopédia do cotidiano - é produzido sob o influxo de interesses, compromissos e paixões. No entanto, não entendemos o jornal Anhanguera como entregue exclusivamente às demandas políticas das facções oligárquicas que controlavam o acesso ao cenário político, pois esse jornal surgiu (em 26 de junho de 1937) e desapareceu (em 14 de setembro de 1937) com uma função bem delimitada: divulgar o ideário bandeirista. Apesar de sua breve circulação, o jornal Anhanguera nos ofereceu o panorama da articulação e difusão de leituras sobre o País e os caminhos que a elite dirigente deveria tomar.

Não negamos que o jornal Anhanguera recebia verbas de parte das oligarquias paulistas para apoiar seu projeto; mas é verdade, também, que tal capital não era exclusivo no financiamento, uma vez que encontramos diversos anúncios de empresas públicas e particulares. Optamos por registrar algumas: Banco do Estado de São Paulo, Viação Aérea São Paulo (VASP), Instituto Nacional de Previdência, Estrada de Ferro Sorocaba, cervejarias Antártica e Brahma. Além desses anúncios, encontramos outros divulgando conserto de chapéus, eletrodomésticos, isqueiros, automóveis e de profissionais liberais. A partir do n. 31, de 2 de agosto 1937, o jornal reservou uma parte da página quatro para anunciantes, tendo como título, "Indicador profissional". A partir do n. 40, de 12 de agosto de 1937, o número de anúncios no jornal é explicitamente duplicado, o que demonstra uma possivel circulação mais abrangente do periódico. Podemos considerar que, no decorrer das edições do jornal, o número de seus leitores se ampliou, pois os redatores informavam que exemplares do jornal eram enviados para Minas Gerais, Goiás, Santa Catarina e estados do Nordeste. Mesmo que tivesse sido apenas uma jogada publicitária para criar uma atmosfera de adesão ao Movimento Bandeira, consideramos que essa estratégia serviu para atrair novos anunciantes.

A partir do n. 24, de 24 de julho de 1937, o jornal traz como novidade o suplemento feminino "Yara", escrito por Maria Antonieta Silva Medeiros, diretora do Instituto "Sanitas" e membro do Departamento Feminino da Bandeira. A partir do n. 18, de 17 de julho de 1937, aos sábados, os redatores incluiram a seção "O Curupira", como suplemento semanal, sempre com publicação de contos e crônicas e, a partir do n. 48, de 21 de agosto, o corpo editorial acrescenta um suplemento direcionado para crianças intitulado "Bichano".

Na primeira página do jornal, costumavam ser publicadas criticas às "ideologias forasteiras", notícias sobre as Forças Armadas, informações sobre o processo eleitoral à Presidência da República e algumas chamadas de notícias que seriam abordadas no decorrer da edição. A segunda página era constituida por noticias de outros jornais ${ }^{7}$, as quais eram reunidas no editorial "Em dia com a opinião nacional", e nas colunas "Faiscando" e "Panorama". Na terceira página eram publicadas moções de apoio de personalidades ao ideário dos "novos bandeirantes" e a repercussão desse ideário em outros estados. Nessa página, encontrávamos a coluna intitulada "Ensaio de exposição do pensamento Bandeirante", a qual era uma espécie de orientação pedagógica sobre o ideário do grupo. A quarta página se ocupava de notícias relacionadas ao teatro, cinema, música e

\footnotetext{
7 As notícias eram retiradas do Diário de Notícias, Gazeta de Notícias, Correio do Paraná, A Ordem, O Estado, A Voz de Vera Cruz, Jornal do Brasil, A Noite, O Globo, A Nação e A Batalha.
} 
sociedade. Já a quinta página mesclava notícias nacionais e internacionais. A sexta e a sétima página informava sobre esporte, principalmente futebol e turfe. Na oitava e, última página, retornava a publicação de notícias nacionais e internacionais.

É possivel perceber que no decorrer de suas edições, esse jornal foi se transformando, fazendo acréscimos constantes de novos suplementos, anúncios e repartições típicas de diários convencionais. Apesar de a organização do diário ser um espaço de combate às "ideologias forasteiras", o Anhanguera começa a se organizar também como um jornal que busca atender a um público heterogêneo como, por exemplo, o público feminino, infantil, comerciantes e pessoas interessadas por esporte e literatura.

No primeiro número do jornal, em 26 de junho de 1937, os redatores expõem no editorial "Nós" as diretrizes fundamentais do Movimento Bandeira. Nesse editorial, os redatores afirmavam que o movimento e o diário defenderiam o Brasil "contra todas as deformações e contra todos os deformadores" (NÓS..., 1937, p. 1). Os bandeiristas defendiam a ideia de "um Brasil nosso, nem deformado pelo utopismo catastrófico da esquerda, nem pela teorização da violência preconizada pela direita" (NÓS..., 1937, p. 1). Esse enunciado fazia referência ao quinto bandeirante inserido na versão de 1936 do poema Martim Cererê de Cassiano Ricardo, onde o herói se encontra dividido entre o "fantasma" da direita e o da esquerda, mas que prefere "andar em linha reta". Assim como no campo literário, os "novos bandeirantes" - atuando no campo político afirmavam, por meio das páginas do diário, que o seu caminho é "do centro, traçado pela reta histórica que o Brasil riscou entre as suas origens e o seu destino" (NÓS..., 1937, p. 1).

Além de exaltar as supostas origens históricas do Movimento Bandeira, encontramos diversos comentários sobre a situação político-partidária brasileira da década de 1930. Através dos editoriais do jornal Anhanguera, os signatários do movimento afirmavam que a "democracia adoece quando lhe falta um conteúdo ideológico e quando dispensa suas forças no centrifugo fracionamento dos partidos" (DEMOCRACIA..., 1937. p. 1). Na coluna "Ensaio de exposição do pensamento Bandeirante", Menotti del Picchia reafirmava que o movimento "não é, nem será, um partido político. É um convite à meditação, um apelo à inteligências" (PICCHIA, 1937, p. 3). Segundo essas proposições, o Movimento Bandeira "chama todos os brasileiros a cooperar na reorganização nacional", pois ele está "acima dos partidos, criando o campo neutro" de ação política (PICCHIA, 1937, p. 3).

Criar conscientemente uma alma, trabalho e disciplina, segundo Júlio Barata (BARATA, 1937, p. 3), são as contribuições dos "novos bandeirantes" para toda a Nação. Completando suas palavras, Manuel Duarte (DUARTE, 1937, p. 3) lembrava que a ação herdada pelos bandeirantes de hoje reencenaria as aspirações do passado. Já, Guaracy Silveira, reforçava o papel de São Paulo como o responsável por guiar a Nação contra os "falsos apóstolos da democracia" (SILVEIRA, 1937, p. 3). Na continuidade da exaltação dos pontos positivos do movimento, Menotti del Picchia destacava o fato de que o ideário dos "novos bandeirantes" transcendia a representação partidária. Como haviamos considerado, para esses simpatizantes do ideário bandeirista, a recuperação da tradição no Brasil moderno é um dos principais pilares do discurso ideológico do Movimento Bandeira. Vejamos, no próximo tópico, como o jornal Anhanguera divulgava a recepção desse ideário entre militares e civis no segundo semestre de 1937.

\section{Repercussão do ideário dos "novos} bandeirantes" entre militares e civis

O prestígio das Forças Armadas para os bandeiristas já poderia ser encontrado nas páginas da revista S. Paulo (1936). Em diversos momentos, os militares eram valorizados pelos bandeiristas, pois, segundo eles, a Marinha e o Exército seriam as únicas instituição capazes de proteger o Estado, a ordem e a lei. Com o intuito de arregimentar seus representantes, o jornal Anhanguera informava que o programa bandeirista foi enviado para vários oficiais.

Como resposta a oferta do programa, os 
generais Eurico Gaspar Dutra e Guedes de Fontoura ofereceram as suas saudações - reproduzidas no periódico - e o elogio do Exército a esses intelectuais que haviam formado um "movimento que visa[va] defender nossa democracia" contra as "doutrinas exóticas" (FONTOURA, 1937, p. 3). O general Góes Monteiro também enviou telegrama ao jornal, onde apoiava o movimento que havia retomado as tradições brasileiras. O general Moreira Guimarães expõe sua opinião no artigo "Bandeira e o Exército" enviado ao Diário Popular, o qual é prontamente transcrito no jornal Anhanguera. Nesse artigo, o general comentava que esse grupo buscava realizar a "ordem pelo Brasil em fora, ordem, muita ordem, sempre a ordem, sem a qual nada será possivel" (GUIMARÃES, 1937. p. 3). Na reportagem, "Movimento da Bandeira julgado por um militar", o Major Carlos Villaça defendia essa "entidade Cultural" por duas razões: por estar "fora dos partidos" e por reconhecer o "penhor da tradição de nossos antepassados" (VILLAÇA, 1937, p. 3). Para esse oficial, "os maiores vultos civis e militares do país receberam com grande simpatia esse movimento", pois, com esse grupo, todos poderiam ir "pela estrada do centro nos destinos da Pátria, fugindo dos atalhos desconhecidos, acenados [...] pelos extremistas" (VILLAÇA, 1937, p. 3).

Podemos inferir que as charges ${ }^{8}$ reproduzidas no jornal Anhanguera apresentam uma especificidade: elas pretenderam se constituir como um instrumento de persuasão, intervindo no processo de definição política e ideológica do receptor. 0 recurso à "charge editorial" é encontrado em todas as edições do jornal Anhanguera e, por essa razão, sua leitura é útil para apresentar as estratégias utilizadas na divulgação do ideário bandeirista. Um exemplo dessa perspectiva pode ser visualizado na charge da Figura 1, pois ela exprimia as tentativas de persuasão do Comunismo e do Integralismo às Forças Armadas. Vejamos:
Figura 1 - Charge Comunismo e Integralismo às Forças Armadas

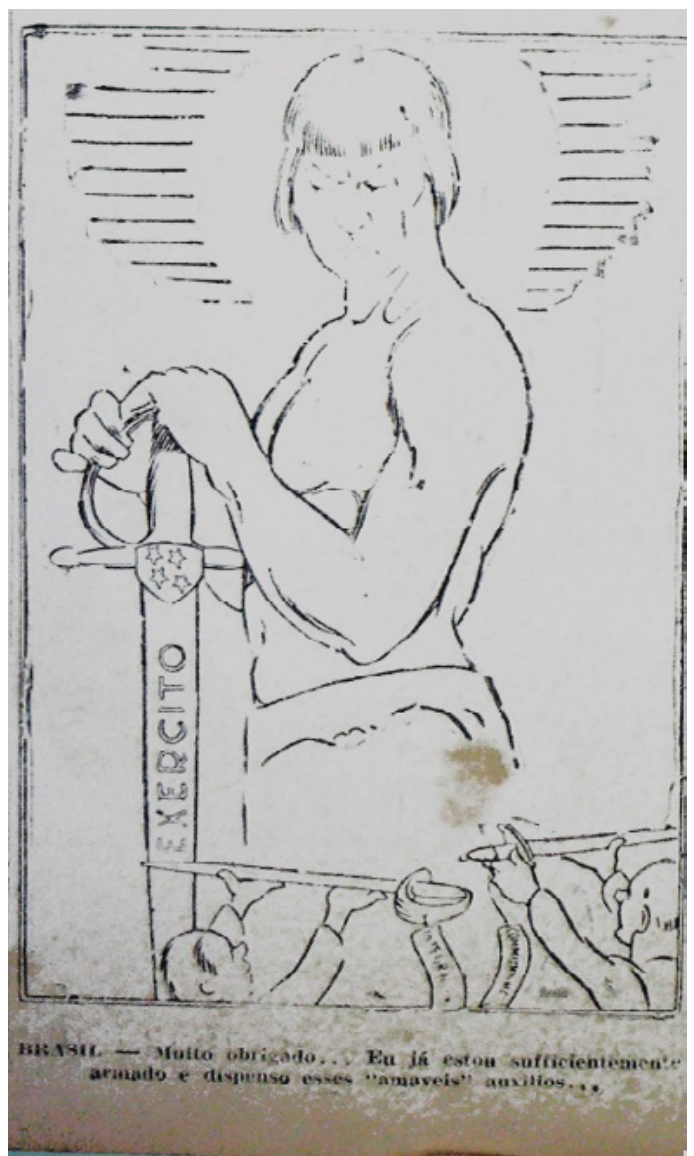

Fonte: Jornal Anhanguera, São Paulo, 20 de ag. 1937, p. 1.

Nessa charge, um integralista e um comunista oferecem suas armas - a espada como símbolo de virtude, bravura e poder - para o Exército, mas esse se recusa a aceitá-la, pois já está "suficientemente armado e dispensa esses 'amáveis' auxilios..." (ANHANGUERA, 1937, p. 1). As charges encontradas no jornal Anhanguera geralmente eram acompanhadas de algumas palavras ou frases, as quais agiam como forma de orientar o leitor em sua interpretação. De acordo com Rozinaldo A. Miani (2012), os elementos linguísticos que acompanham as charges tornam-se importantes para explicitar a sua intencionalidade ou completar o sentido

\footnotetext{
8 As criticas aos extremismos de direita e de esquerda sempre foram acompanhadas por charges, mas antes de nos atermos a suas análises, algumas ressalvas são importantes. De acordo com Rozinaldo A. Miani (2012), a charge pode aparecer isolada no contexto de determinada publicação, mas apesar da autonomia interpretativa da charge, não é possivel analisá-la de maneira absolutamente autônoma, uma vez que esse texto participa de um contexto comunicativo maior, pois ela tem uma natureza intertextual. Essa ocorrência é considerada pelo autor como "charge editorial", visto que é reconhecida como um "editorial gráfico". Segundo o autor, a charge é utilizada na sátira política como um "instrumento de crítica e luma] arma retórica de combate, bem como na defesa e divulgação de ideologias, principios e programas" (MIANI, 2012, p. 39).
} 
humoristico e político proposto pela ilustração. Com base nessa reflexão, o elemento linguistico contido nesta charge serviu para demonstrar a recusa do Exército aos dois extremismos, assim como, codificar a posição dos "novos bandeirantes" frente às interferências dos extremismos nas Forças Armadas.

Em relação à posição das Forças Armadas frente às essas ameaças, os "novos bandeirantes" parabenizaram o general Dutra por tomar medidas regulamentares para manter disciplina na corporação. Segundo o próprio general, essas medidas pretenderam extirpar dos quartéis "quaisquer infiltrações dos extremismos da esquerda e da direita" (DUTRA, 1937, p. 1). O jornal também parabenizava o Almirante Aristides Guilhem por haver tomado "medidas para expurgar a armada desses maus elementos" (A ARMADA..., 1937, p. 1). Para os "novos bandeirantes", a "intromissão do Integralismo nas classes militares" merecia "atenção dos poderes constituidos [...] que já tomaram atitude enérgica por ocasião de tentativa idêntica feita pelos adeptos de Moscou" (AARMADA..., 1937, p. 1).

Na obra Ensaio de exposição do pensamento bandeirante (1936), Menotti del Picchia expôs qual seria o papel das Forças Armadas no ideário dos "novos bandeirantes". No tópico "A Bandeira e as Forças Armadas", o ensaísta considerava que o Exército e a Marinha seriam guardas "de todas as realizações da Bandeira" (PICCHIA, 1936, p. 30). O ensaísta via, na "disseminação do espirito militar, a forma mais sadia e operante da interpretação da nacionalidade" (PICCHIA, 1936, p. 30). Para o ensaista, a "caserna" seria a "melhor escola" a fim de fazer penetrar nos espiritos as "ideias de Pátria, de solidariedade", de "cultura", de "disciplina e hierarquia" e, acima de tudo, a "consciência coletiva de brasilidade" (PICCHIA, 1936, p. 30). Para o Movimento Bandeira, os militares combateriam os extremismos, tanto fora quanto dentro da corporação, haja vista que seus representantes não poderiam se envolver em politica partidária. Para que fossem possiveis tais realizações, os bandeiristas consideravam que as Forças Armadas deveriam ser compostas de pessoal "adestrado" - cultural e tecnicamente
- para servir aos interesses nacionais.

Ao lado do apoio advindo de oficiais de alta patente do Exército e da Marinha, representantes da sociedade civil também endossaram as propostas dos "novos bandeirantes" por meio do jornal Anhanguera. Nas palavras de Levi Carneiro - jurista, deputado estadual carioca e membro da $A B L$-, o Movimento Bandeira tinha o mérito de não ser "uma empresa para a conquista do poder, mas um [...] movimento cultural [...] de educação da opinião pública" (CARNEIRO, 1937, p. 3). Clovis Bevilaqua - jurista cearense e membro da ABL - defendia por meio das páginas do jornal que "incentivar esse movimento [era] trabalhar pelo Brasil" (BEVILAQUA, 1937, p. 3). Por telegrama, Gilberto Freire - sociólogo pernambucano - solicitou a inclusão de seu nome entre os colaboradores, declarando-se interessado pelo movimento de cultura e nacionalismo iniciado pelos escritores paulistas.

Além de juristas, deputados e escritores, diversos governadores enviaram moções de apoio ao Movimento Bandeira. Esses representantes do executivo estadual esperavam que o poder público apoiasse a iniciativa do grupo que lutava pela defesa do Brasil contra o pensamento forasteiro. Todos parabenizaram a atitude dos escritores paulistas que defendiam a tradição, as instituições, a cultura e o nacionalismo e, o mais importante, por ser um projeto políticocultural de grande função social. Juntamente com transcrições de apoio dos governadores estaduais, o jornal Anhanguera também divulgava a repercussão do movimento nesses estados. Tal atitude tinha o intuito de reforçar a presença do Movimento Bandeira, não só na região Sudeste, mas em todo território nacional. Com esse recurso, os redatores poderiam demonstrar que esse movimento político-cultural repetiria o avanço das Bandeiras históricas do século XVII.

Ao descrever o apoio ao movimento, os "novos bandeirantes" pretendiam afirmar que eles reviveriam as Bandeiras históricas ao organizarem uma nova marcha predestinada em busca de seu destino nacional. Durante a campanha do Movimento Bandeira, os comentários de seus 
signatários, transcritos no jornal Anhanguera, amplificavam a importância do grupo no cenário nacional. É visivel o apoio de seus colaboradores para que a instituição alcançasse seus objetivos, pois todos se colocavam na cruzada em prol da indole e das tradições do povo brasileiro. Essas moções de apoio ressaltavam a importância dessa quarta via política que se apresentava no campo político em meados da década de 1930. principalmente nos meses que antecederam a eleição presidencial de 1938. Frente a isso, no próximo tópico, discutiremos como os bandeiristas se lançaram na campanha eleitoral em prol da candidatura de Armando de Salles.

\section{Os bandeiristas se lançam na campanha presidencial de 1937}

Como o ano de 1938 seria a primeira experiência eleitoral que a sociedade brasileira teria sob o Sufrágio Eleitoral estipulado pela Lei Eleitoral de 1932. A esse respeito, veremos - por meio da leitura do jornal Anhanguera - que a campanha eleitoral empreendida pelos "novos bandeirantes" no ano de 1937 oferecerá um indicador de parte da opinião pública. De acordo com René Rémond (1996), a campanha eleitoral é parte integrante de uma eleição, ou melhor, é o seu primeiro ato. A campanha não é apenas a "manifestação das preocupações dos eleitores ou a explicação dos programas dos candidatos e dos temas dos partidos, é a entrada em operação de estratégias, a interação entre os cálculos dos políticos e os movimentos de opinião" (RÉMOND, 1996, p. 49). Partido da posição de René Rémond, entendemos que a campanha eleitoral empreendida pelo Movimento Bandeira é um bom exemplo da operação estratégica eleitoral dos bandeiristas na década de 1930.

No editorial intitulado "Duas mentalidades", os redatores bandeiristas criticavam o presidencialismo liberal, dizendo que o representante da Nação "fica tão focalizado pela opinião" que os "atos e suas ideias se refratam no clima político ambiente, moldando-o a sua imagem e semelhança" (DUAS..., 1937. p. 1). Diante desse pressuposto - o de que, na Democracia Liberal, o presidente fica refém da opinião pública -, os bandeiristas expõem seus pontos de vistas a respeito de Getúlio Vargas. Através das páginas do jornal Anhanguera, os redatores informam que Gustavo Barroso acusava que Getúlio Vargas "vê com simpatias a candidatura do chefe verde" (TROCANDO..., 1937, p. 1). De acordo com os redatores bandeiristas, essas aproximações na boca do povo, ganharam múltiplos sentidos. Dizem uns, que Getúlio Vargas quer agradar as "camisas verdes" para

\begin{abstract}
[...] uma possivel convulsão do Brasil [...]. Há quem diga, por exemplo, que o sr. Getúlio dentro das suas normas de "cozinhar em água fria" - percebendo que a candidatura nascida da convenção já está desmoralizada, vê no sr. Plínio Salgado a última possibilidade de pôr no Catete um fantoche que ele poderia manobrar ao seu bel-prazer (TROCANDO..., 1937, p. 1).
\end{abstract}

Com as afirmações de que Vargas queria agradar o Integralismo ou ainda colocar um fantoche no Catete, os colaboradores bandeiristas afirmavam que "a tapeação é um jogo engraçado e confuso" (DUAS,..., 1937, p. 1). A charge na Figura 2 pretende representar as artimanhas de Getúlio Vargas:

Figura 2 - Artimanhas de Getúlio Vargas

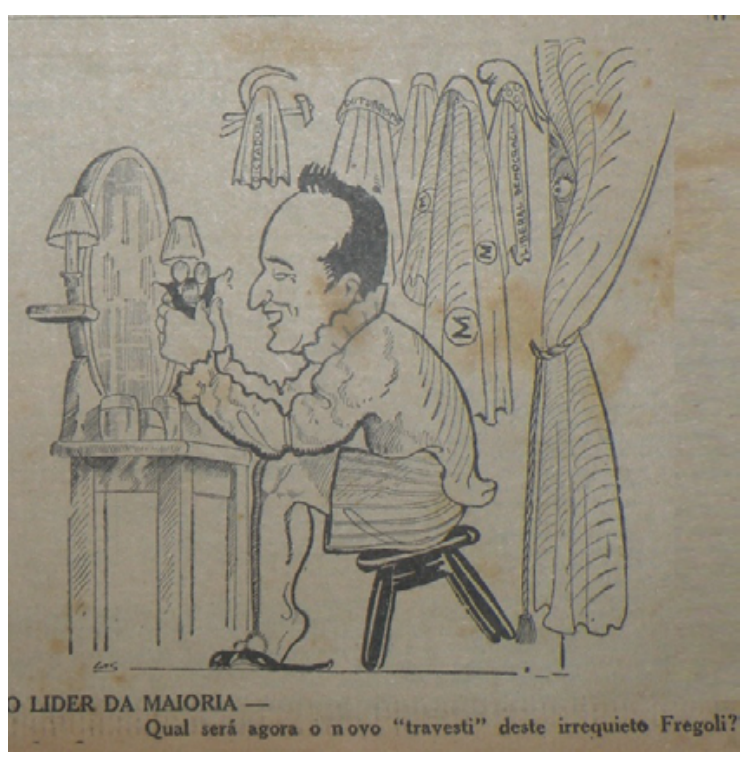

Fonte: Jornal Anhanguera, São Paulo, 29 de jun. 1937, p. 1.

Essa charge ironiza Vargas em seu camarim, brincando com fantoches e com seus disfarces pendurados na parede. Como de costume, nas "charges editoriais" do jornal Anhanguera, o 
ilustrador deixava uma frase para completar sua intertextualidade: "Qual será o novo 'travesti' deste irrequieto Fregoli?" (ANHANGUERA, 1937. p. 1). Os criticos bandeiristas acusavam Vargas através da comparação com Fregoli, um famoso artista de palco conhecido por fazer várias trocas de figurinos em pouco tempo. Além de estar com fantoches nas mãos, Vargas tem, a seu dispor, vários figurinos - ditadura comunista, integralista, liberal democracia, outubrismo - para confundir a opinião pública. Para esses opositores de Vargas, essas atitudes do presidente desorganizavam "o país e acabalm] tornando intranquilos os espiritos" (DUAS..., 1937, p. 1). Outras charges ironizavam as atitudes confusas de Getúlio Vargas como, por exemplo, a da Figura 3, na qual fundem algumas bases do ideário bandeirista.

Figura 3 - Atitudes confusas de Getúlio Vargas

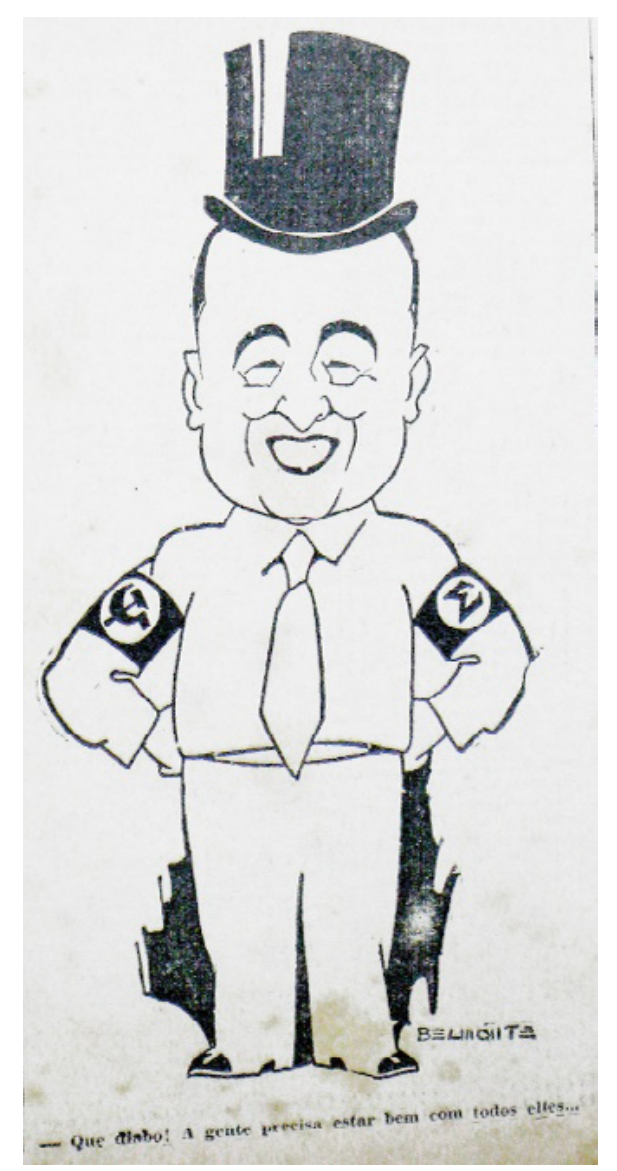

Fonte: Jornal Anhanguera, São Paulo, 19 de jul. 1937, p. 1.

Essa charge ironiza Vargas por meio da cartola da burguesia liberal e dos símbolos comunista e integralista. A ilustração traz o comentário: "- Que diabo! A gente precisa estar bem com todos eles..." (ANHANGUERA..., 1937, p. 1). Diante das dúvidas a respeito das posições de Getúlio Vargas, a coluna "Faiscando" afirma que o "presidente [...] veste, agora, por esporte, a camisa verde" (FAISCANDO..., 1937. p. 2). De modo geral, os bandeiristas ironizavam os malabarismos varguistas, apontando-os como exemplo da incerteza pessoal que, de certo modo, é o principal responsável pela instabilidade do regime democrático brasileiro.

Também são claras as preocupação dos "novos bandeirantes" sobre o fato que "o sr. Getúlio Vargas está intervindo abertamente na campanha presidencial" (O SR...., 1937, p. 1). Os "novos bandeirantes" afirmavam que, ao influir na vida partidária, Vargas tornou-se "o mais desprezado politiqueiro que já se hospedlara] no palácio do Catete" (EM..., 1937, p. 2). As criticas endurecem, pois Vargas "está disposto a provocar uma revolução de maneira a tornar-se novamente ditador" (COMO..., 1937, p. 5). Eles criticavam as indecisões do presidente no contexto político da época, uma vez que sua oposição frente ao Comunismo era conhecida, mas em relação ao Fascismo/ Integralismo, incerta. Os lideres do Movimento Bandeira acusavam-no de aproximação ao "nazismo-Integralismo", da instabilidade política e do ataque à ordem derivada da falta de uma posição política definida. De qualquer forma, o principal temor dos "novos bandeirantes" dizia respeito às supostas intervenções de Vargas na sucessão presidencial e as suas intenções de se perpetuar no governo.

Outras reportagens encontradas no jornal bandeirista destacavam como a candidatura de Armando de Salles repercutia em todas as camadas sociais. No campo das disputas políticas de meados da década de 1930, os "novos bandeirantes" se colocavam como quarta via frente à proximidade da sucessão presidencial marcada para 1938. Os redatores explicavam que esse grupo defendia a candidatura de Armando de Salles à presidência, justificando que esse político era a "expressão do rejuvenescimento da democracia" contra a "ameaçadora barbárie integralista- 
comunista" (CONGREGAM-SE..., 1937, p. 3). Com base nesse projeto, o Movimento Bandeira apoiava a candidatura de Armando de Salles não somente para por o projeto bandeirista em ação, mas para a consolidação do projeto paulista e devolução do seu papel de destaque no campo político nacional. Nesse sentido, torna-se interessante apresentar como os bandeiristas construiram o apoio da candidatura de Armando de Salles.

Segundo Antônio Carlos Pacheco Silva (1980), Armando de Salles surgiu no cenário político do país como uma figura oracular, relembrando os feitos heroicos dos bandeirantes para atualizar o papel que tiveram na formação da nacionalidade. Mesmo recuperando simbolicamente o passado paulista, Armando de Salles, ao assumir a interventoria paulista em 1934, de acordo com Carolina Soares Sousa (2013), tornou-se prisioneiro da aliança com Getúlio Vargas. Apesar dessa situação, ao final de 1936, o político paulista antecipa-se ao debate sucessório e se apoia em um dos principais dilemas do projeto político e econômico paulista: a dificuldade de conciliar autonomia regional com fortalecimento do poder central. Antes de renunciar ao cargo de Governador do Estado em 1937, Armando de Salles havia previamente consultado Getúlio Vargas, o qual the deu, nessa ocasião, a certeza do seu propósito de presidir com imparcialidade as eleições que deveriam realizar-se de acordo com disposição expressa da Carta Constitucional, promessa que Vargas não cumpriria (SILVA, 1980). Em maio de 1937, o Partido Constitucionalista lançou a candidatura de Armando de Salles para presidente da República nas eleições que deveriam realizar-se a 3 de janeiro de 1938. Armando de Salles dirigiu um manifesto à nação convocando seus partidários a realizar um Congresso Extraordinário do Partido para ratificar sua escolha como candidato.

Para Carolina Soares Souza (2013), a atuação de Armando de Salles e seu projeto político tinham dimensões de envergadura nacional, o qual está presente em seus pronunciamentos, tanto como interventor em São Paulo quanto nas duas campanhas eleitorais que enfrentou, uma para o governo paulista em 1934 e outra para presidente em 1937. Segundo a autora, seus discursos eram marcados pelo enfoque da necessidade de organizar politicamente o país e pela insistência na ideia de que o cerne do problema brasileiro estava não na organização das classes, mas na falta de um partido nacional. No que se refere à constituição de uma nova cultura política, Armando de Salles conseguiu dar condições para formar uma cultura de oposição ao varguismo, oposição que contou com a colaboração dos "novos bandeirantes".

Maria do Carmo Campello de Souza (1990) considera que esse sentimento de exclusão das elites regionais face ao governo central era geral, pois os representantes das mais diversas correntes estavam temerosos em razão da crescente marginalização face às medidas centralizadoras do governo varguista. As crises políticas desse periodo podem ser vistas como consequências das tentativas de institucionalizar um poder pós-revolucionários sobre uma estrutura politica regional. Para a autora, "mesmo os liberais mais convictos pareclialm incapazes de visualizar uma nova etapa de desenvolvimento político, fundada em partidos de base social mais extensa" (SOUZA, 1990, p. 80).

No artigo "Um candidato para o Brasil", publicado no jornal Anhanguera, os redatores avaliaram a campanha eleitoral no Brasil; para tanto, retomam às origens do Liberalismo brasileiro a fim de demonstrar a inutilidade da Democracia Liberal na "hora atual". O argumento da inutilidade da Democracia Liberal abria caminhos para defender a vantagem da candidatura de Armando de Salles, pois esse candidato "representalval uma orientação construtiva" (UM..., 1937, p. 1). Ressaltavam, também, que o "candidato bandeirante" enfrentava "candidatos messiânicos e caricaturais", de modo que somente Armando de Salles venceria "como um candidato do Brasil moderno" (UM..., 1937, p. 1). No que se refere à campanha do candidato paulista, os redatores lembram: "S. Paulo que já é a maior força econômica e cultural do país, empenha-se agora em adquirir a liderança também no campo político" (UM..., 1937, p. 1). Aqui podemos 
perceber como os "novos bandeirantes" buscavam reinserir São Paulo no controle político nacional, uma vez que, após a "Revolução de 30", a derrota na Revolta de 1932 e a contribuição paulista na Constituição de 1934, os bandeiristas esperavam, com a campanha presidencial e a expectativa de eleição de Armando de Salles, retomar o controle político da Nação.

Como foi possivel perceber, o Movimento Bandeira fortaleceu-se no contexto da campanha presidencial no segundo semestre de 1937. Ao construírem o ideário do movimento, esses intelectuais se apropriaram do "mito bandeirante" e o transferiu para os debates do campo político de meados da década de 1930. Frente ao clima de tensão da sucessão presidencial, os "novos bandeirantes" inseriram em seu discurso questões como o "perigo comunista", as "ameaças nazistas", a "agressividade do Integralismo", as "interferências de Vargas no pleito presidencial" e o papel das Forças Armadas na defesa da ordem. Além dessas questões, os "novos bandeirantes" também defendiam a instauração de um "Estado Forte" que sobressaísse às experiências da Democracia Liberal presente na República. Para eles, somente essa proposta poderia criar uma Democracia Social Nacionalista que disciplinaria os interesses individuais em prol da Nação.

Frente à campanha política da sucessão presidencial no segundo semestre de 1937, na qual era disputada pelas candidaturas de Armando de Salles, Plinio Salgado e José Américo, Boris Fausto (2000) considera que faltava um pretexto para Getúlio Vargas reacender o clima golpista, pois estava ciente de que o poder escaparia de suas mãos. O Plano Cohen pretendeu forjar uma suposta insurreição comunista. Esse plano passou para as mãos da alta cúpula do Exército e, em 30 de setembro, foi divulgado em programas oficiais pelo rádio e jornais. Em fins de outubro, o deputado Negrão de Lima percorreu os estados do Norte e do Nordeste para garantir o apoio dos governadores ao golpe planejado por Vargas. Somente no início de novembro de 1937 a oposição ao golpe se mobilizou. Armando de Salles lançou um manifesto aos chefes militares apelando para que impedissem a execução do golpe. De acordo com o autor, esse ato serviu apenas para apressar o golpe sob a alegação de que clima de desordem estava chegando ao extremismo. Em plena campanha presidencial, Getúlio Vargas faz uma proclamação - "O prefácio do Estado Novo" -, em 10 de novembro de 1937. que mudaria o curso dos acontecimentos. Nela, o presidente informa que, em virtude da "profunda perturbação política, econômica e social" e das "solicitações do interesse coletivo", o Governo Federal havia adotado medidas que afetavam as "convenções do regime", decretando assim o golpe que instituiu do Estado Novo.

Segundo Rogério Lustosa Victor (2012), a expectativa de "um futuro radiante" com a candidatura de Plínio Salgado à Presidência da República no ano de 1938 era muito grande. Para o autor, o golpe de 37 não havia significado a interdição da "expectativa de futuro" que os integralistas haviam construido. Uma das explicações dadas por Rogério Victor para o retardo da frustração dos integralistas é que a Ação Integralista Brasileira (AIB) havia corroborado com a implantação da ditadura. O autor afirma que as negociações entre o líder integralista e os agentes da ditadura continuaram em curso após a instauração do Estado Novo. Mesmo assim, a perspectiva de futuro se distanciava do horizonte integralista, pois os integralistas perceberam o silêncio de Vargas sobre o AIB no discurso de 10 de novembro. De qualquer modo, o autor considera que Plínio Salgado preparavase para organizar a base do partido único da ditadura, mas o plano de Vargas era extinguir o Integralismo. O Decreto-Lei n. 37 dissolveu todos os partidos e, com isso, a AIB deveria se transformar em uma sociedade civil e mudar de nome. Victor (2012) lembra que Plínio Salgado esforçou-se para enquadrar seu movimento à nova situação, inclusive mudando o nome para Associação Brasileira de Cultura (ABC).

No primeiro semestre de 1938, o sentimento de traição dos integralistas despertou um estado de revolta que os levaram ao levante armado. Com o fracasso do levante de 11 de 
maio de 1938, Victor (2012) lembra que o Estado Novo empreendeu ampla campanha contra os integralistas, apontando Plínio Salgado e outros integralistas como criminosos. Sem a "força política" que Vargas pretendia arregimentar para o seu lado, o Estado Novo passou a incorporar outros intelectuais a sua máquina de propaganda. Entre os quais, encontramos antigos parceiros de caneta e rivais políticos de Plinio Salgado: Cassiano Ricardo, Menotti del Picchia, Candido Motta Filho, além de outros bandeiristas.

Uma semana após a tentativa do golpe integralista de 11 de maio de 1838. Ademar de Barros envia carta a Getúlio dando "bons antecedentes" de Cassiano Ricardo. Nesse mesmo ano, Luiz Vergara, então secretário de Getúlio Vargas, consulta Cassiano Ricardo sobre um possivel encontro dele com o presidente, a quem João Neves havia mostrado um exemplar de 0 Brasil no original (1937). O poeta, acompanhado por Menotti del Picchia, é recebido por Vargas e, da conversa, surge a constatação de que havia pontos de contato entre o pensamento político bandeirista e o Estado Novo. Em 1939 Cassiano Ricardo muda-se para o Rio, onde passa a trabalhar na elaboração da revista de rotogravura Brasil Novo, a qual tinha o intuito de divulgar o novo regime. Ao retornar para São Paulo, assume a direção do Departamento Estadual do DIP e dirige a revista Planalto, também de cunho propagandístico do Estado Novo. Aproximando ainda mais os laços com o Estado Novo, Cassiano Ricardo retorna ao Rio de Janeiro em 1941 e assume, a convite de Getúlio Vargas, a direção do jornal governista $A$ Manhã.

\section{Considerações finais}

Em uma sociedade que dá prioridade à escrita, o interesse pelas informações divulgadas pelos jornais oferece um ponto de vista capaz de promover a compreensão das experiências dos individuos e grupos. Apesar dessa especificidade, é preciso alertar para o fato de que o jornal reproduz parcialmente tais experiências, uma vez que, os grupos detentores do poder trabalham para convergir, no espaço da imprensa, não apenas seus interesses, mas os enunciados por meio dos quais tais interesses serão consumidos e incorporados pelo público leitor. Segundo Ciro Marcondes Filho (1989), a busca de visões difundidas pelos jornais se torna importante, pois a imprensa é um campo de batalha, espaço onde indivíduos e grupos afirmam publicamente suas opiniões. Para o autor, o jornalismo e os meios de informação procuram preservar certa impessoalidade capaz de afirmar seu poder e soberania através da construção de uma "verdade" planejada e uma reprodução parcial da realidade em questão, ancorada na passividade, acomodação e a apatia em seus receptores. A partir dessa consideração do autor, podemos abri um diálogo com Tânia Regina de Luca (2008) ao entendermos que a imprensa periódica seleciona, ordena, estrutura e narra, de determinada forma, aquilo que se elegeu como digno de chegar até o público e, além disso, problematiza a identificação imediata e linear entre a narração do acontecimento e o próprio acontecimento.

No caso especifico do jornal Anhanguera, seus organizadores utilizavam esse periódico para expor a base ideológica dos bandeiristas, isto é, o combate às "pragas políticas", a instauração de um Estado Forte e da Democracia Social Nacionalista. Além desse combate, também foi possivel esclarecer o ponto de vista dos "novos bandeirantes" sobre o papel das Forças Armadas, a oposição ao Comunismo, ao Integralismo e à Democracia Liberal. Por meio desse jornal, os bandeiristas também criticavam a atuação de Getúlio Vargas na política e a defesa da candidatura de Armando de Salles à Presidência da República.

Considerando que o jornal Anhanguera foi a principal forma de arregimentação de adeptos ao Movimento Bandeira, vemos esse periódico como espaço de diálogo literário e político, e mais, encontramos a atuação de Cassiano Ricardo como agente político na articulação desse grupo, daí a viabilidade da noção de "sociedade de individuos" de Norbert Elias para entendermos a habitus social desse intelectual. Foi possivel perceber que outros escritores, políticos e militares aos poucos vão se articulando com as 
propostas do Movimento Bandeira, as quais tem em Cassiano Ricardo seu principal articulador.

Com base no apoio de intelectuais, políticos, governadores, ministros e de generais, é possivel traçar - a partir da leitura desse periódico algumas caracteristicas dos seus interlocutores. Todas as adesões convergiam para alguns pontos em comum: exaltavam o empréstimo do passado histórico paulista para todo o Brasil, aplaudiam a "função patriótica" dos fundadores do movimento e o resgate da tradição como útil à Nação. Para esses signatários, a maior vantagem do grupo era estar "fora do jogo partidário", pois com essa postura, poderiam - juntamente com intelectuais, políticos e militares - combater as "ideologias forasteiras". De modo geral, vemos como se articulou uma "sociedade de individuos" entorno do jornal Anhanguera, a qual tem como habitus social a apropriação política das representações literárias sobre o bandeirante. Acreditamos que, frente à dificuldade de criar partidos nacionais, à falta de conteúdo ideológico que arregimentasse a sociedade nesses partidos, à tendência autoritária que predominava nesses anos, à oposição a organizações vistas como inimigas da nacionalidade - a AIB e o Comunismo - e ao descrédito com a Democracia Liberal, a análise do periódico em questão nos ofereceu indícios de como os "novos bandeirantes" se apresentaram como uma organização cultural de caráter nacional capaz de solucionar os problemas nacionais.

\section{Referências}

A ARMADA vai ser expurgada dos elementos integralistas que procuram conspurca-la. Anhanguera, São Paulo, 18 ago. 1937, p. 1.

ANHANGUERA. Anhanguera, São Paulo, 19jul. 1937, p. 1. ANHANGUERA. Anhanguera, São Paulo, 20 ago. 1937, p. 1. ANHANGUERA. Anhanguera, São Paulo, 29jun. 1937, p. 1.

BARATA, Júlio. Dando Alma ao Brasil. Anhanguera, São Paulo, 4 jul. 1937, p. 3

BEVILAQUA, Clovis. Anhanguera, São Paulo, 27 jul. 1937, p. 3.

CARNEIRO, Levi. Anhanguera, São Paulo, 26 jul. 1937, p. 3.
CHARTIER, Roger. À Beira da Falésia: a História entre Certezas e Inquietudes. Trad. Patrícia Chittoni Ramos. Porto Alegre: Ed. Universidade/UFRGS, 2002. 277 p.

COMO O SR. GETÚLIO VARGAS pretende criar razões que justifiquem a sua ostensiva intervenção no pleito presidencial. Anhanguera, São Paulo, 2 ago. 1937. Editorial, p. 5.

CONGREGAM-SE os estudantes de piracicaba, para a defesa da democracia. Anhanguera, São Paulo, 5 ago. 1937, p. 3.

DEMOCRACIA. Anhanguera, São Paulo, 5 jul. 1937, Editorial, p. 1.

DUARTE, Manuel. Bandeirantes. Anhanguera, São Paulo, 26 jun. 1937, p. 3.

DUAS MENTALIDADES. Anhanguera, São Paulo, 30 jul. 1937, Editorial, p. 1.

DUAS MENTALIDADES. Anhanguera, são Paulo, 30 jun. 1937, Editorial, p. 1.

Dutra, Eurico Gaspar. Anhanguera, São Paulo, 5 ago. 1937, p. 1.

ELIAS, Norbert. A sociedade dos individuos. Rio de Janeiro: Zahar, 1994.

EM DIA COM A OPINIÃO NACIONAL. Anhanguera, São Paulo, 3 jul. 1937, p. 2.

FAISCANDO. Anhanguera, São Paulo, 2 jul. 1937, p. 2.

FAUSTO, Boris. História Concisa do Brasil. São Paulo: EDUSP/IMESP, 2000. 328 p.

FILHO, Ciro Marcondes. O capital da notícia. São Paulo: Ática, 1989. 188 p.

FONTOURA, Guedes de. Anhanguera, São Paulo, 29 jun. 1937, p. 3

GOMES, Ângela Maria de Castro (coord.). Regionalismo e centralização política. Rio de Janeiro: Nova Fronteira, 1980. $501 \mathrm{p}$.

GUELFI, Maria Lúcia Fernandes. Novíssima: estética e ideologia na década de vinte. São Paulo: Instituto de Estudos Brasileiros, 1987. 264 p.

GUIMARÃES, Moreira. Bandeira e o Exército. Anhanguera, São Paulo, 26 jul. 1937, p. 3.

LUCA, Tania. Regina de. História dos, nos e por meio dos periódicos 2. ed. In: PINSKY, Carla Bassanezi (org.). Fontes Históricas. 2. ed. São Paulo: Contexto, 2008. v. 1. p. 111-153.

MENDONÇA, Sônia Regina de. Estado e sociedade: a consolidação da República oligárquica In: LINHARES, Maria Yedda (org.). História geral do Brasil: da colonização portuguesa à modernização autoritária. 9. ed. Rio de Janeiro: Campus, 1990. p. 315-326

MIANI, Rozinaldo Antônio. Charge: uma prática discursiva e ideológica. Disponivel em: http://wwwz.eca.usp. br/nonaarte/ojs/index.php/nonaarte/article/view/3. Acesso em: 20 abr. 2015. 
MICELI, Sérgio. Imagens negociadas: retratos da elite brasileira (1920-1940). São Paulo: Companhia das Letras, 1996. 174 p.

MONTEIRO, Amilton Maciel. Cassiano: fragmentos para uma biografia. São José dos Campos, SP: Univap, 2003. 424 p.

NÓS. Anhanguera, São Paulo, 26 jun. 1937, Editorial, p. 1.

O SR. GETÚLIO VARGAS ESTÁ INTERVINDO ABERTAMETNE NA CAMPANHA ELEITORAL. Anhanguera, São Paulo, 3 ago. 1937, p. 1.

OLIVEIRA, Lúcia Lippi de (coord.). Elite Intelectual e debate politico nos anos 30: uma bibliografia comentada da revolução de 1930. Rio de Janeiro: INL, 1980. 356 p.

PICCHIA, Menotti del. Ensaio de exposição do pensamento bandeirante. São Paulo: Revista dos tribunais, 1936. $48 \mathrm{p}$.

PICCHIA, Menotti del. Ensaio de exposição do pensamento Bandeirante. Anhanguera, São Paulo, 5 jul. 1937, p. 3

PICCHIA, Menotti del.; RICARDO, Cassiano.; SALGADO, Plinio Salgado. O Curupira e o Carão. São Paulo: Editora Hélios, 1927.

RÉMOND, René. As eleições. In: RÉMOND, René (org.). Por uma História política. Trad. Dora Rocha. Rio de Janeiro: Editora UFRJ, 1996. p. 37-55

SERVA, Mário Pinto. Anhanguera, São Paulo, 1 jul. 1937, p. 4

SILVA, Antônio Carlos Pacheco e. Armando de Salles Oliveira. São Paulo: Editora USP, 1980. 179 p.

SILVEIRA, Guaracy. Anhanguera, São Paulo, 7 jul. 1937, p. 3.

SOUZA, Carolina Soares. "Para que o Brasil continue". Armando de Salles Oliveira e a comunidade politica do jornal O Estado de S. Paulo: entre a memória e a história (1933-1945). Disponivel em: http://www.snh2013.anpuh. org/resources/anais/27/1364922151_ARQUIVO_TextoAnpuh2013.pdf. Acesso em: 08 abr. 2015

SOUZA, Maria do Carmo Campello. Estado e partidos políticos no Brasil (1930 a 1964). 3. ed. São Paul: Editora Alfa-Omega, 1990. 178 p.

TROCANDO O SR. JOPSÉ AMÉRICO PELO SR. PLÍNIO SALGADO. Anhanguera, São Paulo, 21 jul. 1937, p. 1.

UM CANDIDATO PRA O BRASIL. Anhanguera, São Paulo, 29 de jun. 1937, p. 1.

VICTOR, Rogério Lustosa. O labirinto integralista: o PRP e o conflito de memórias (1938-1962). 2012. 302 f. Tese (História) -- Departamento de História, Universidade Federal do Goiás, Goiânia, 2012.

VILLAÇA, Carlos. Movimento da Bandeira julgado por um militar. Anhanguera, São Paulo, 1 jul. 1937, p. 3.

\section{George Leonardo Seabra Coelho}

Pós-doutor em História pela Universidade Federal do Estado do Rio de Janeiro (UNIRIO, Rio de Janeiro, RJ Brasil), Doutor em História pela Universidade Federal de Goiás (UFG, Goiânia, GO, Brasil), professor Adjunto da Universidade Federal do Tocantins (UFT, em Porto Nacional, TO, Brasil).

\section{Endereço para correspondência}

George Leonardo Seabra Coelho

Universidade Federal do Tocantins

Rua 03, Quadra 17, Lote 11, S/N, Coordenação de História

Jardim do Ipês I CEP 77500-000

Porto Nacional, TO, Brasil 